\title{
Uma "outra" São Paulo da década de 1930
}

Vantuil PEREIRA

FAUSTO, Boris. O crime do restaurante chinês. São Paulo: Companhia das Letras, 2009, 246 p.

A década de 1930 sempre exerceu certo enlevo para quem estuda a História do Brasil Contemporâneo. Em grande medida, a Revolução de 1930 pautou tanto as ações políticas, quanto as ações acadêmicas. Assim, no campo acadêmico, olhar para aquele decênio significa tentar compreender fenômenos como o populismo, o estudo das "modernas" formas de fazer política, o estilo constituinte dos partidos contemporâneos.

É resultado deste período a estruturação daquilo que Wanderley Guilherme dos Santos denominara "cidadania regulada", isto é, uma inserção social controlada pelo Estado, no qual os direitos inerentes de cidadania são constituídos de forma parciais e com uma clara intenção homeopáticas.

A essa época consta também os traços ou resquícios de um tempo não muito distante. Pertencem a mesma década as principais formulações racistas e autoritárias, expressas na eugenia ou na proposição de que não haveria um sentimento de povo no Brasil, apenas visões parciais e localistas. Por seu turno, a sociedade não estaria preparada para o exercício político; não estava acostumada com instituições democráticas. Do mesmo modo, o pensamento científico ganhava terreno, ampliando suas relações socais concretas.

Diferentemente de verificar como um Estado autoritário impactou na vida de um militante comunista ou sindicalista, esta historiografia deixa de olhar como estas instituições impactaram no cotidiano das pessoas comuns. Embora as ideias racistas não tivessem sido introduzidas no Brasil naquela época, foi em 30 que as discussões raciais ganharam terreno. Elas resultaram de uma articulação entre a academia e a vida cotidiana da população através dos aparelhos repressivos que, mediado pelo Estado, interferiram no dia-a-dia da população.

Ao lançar vistas para os anos de 1930, tem-se pelo menos dois outros aspectos instigantes. O primeiro se refere a uma preocupação principal com a construção do edifício e as bases do Estado moderno nacional, seja pelo viés industrial e urbano, seja pelo pensamento político e jurídico daí emanado. Em segundo lugar, dá-se ênfase a compreensão do fenômeno político que foi Getulio Vargas, uma espécie de mito moderno o qual, ao longo das décadas seguintes à sua chegada ao poder, acabou por instituir uma espécie de paradigma político e social na história recente do país.

- Professor Doutor - Departamento de História e do Programa de Pós-Graduação em História - UFRJ - Univ. Federal do Rio de Janeiro - Av. Pasteur, 250, CEP: 22290-240, Rio de Janeiro, Rio de Janeiro, Brasil. E-mail: vantuilpereira@yahoo.com.br 
Desse modo, frequentemente a história política dos anos 30 esteve às voltas com as narrativas das grandes personalidades que, obviamente, não se restringiam à persona de Getúlio, podendo-se falar em figuras como Gustavo Capanema, Juarez Távora, Francisco Campos, etc. Portanto, tratarse-ia de um enfoque histórico a partir dos grandes homens ou, no mais das vezes, de uma história política renovada que procurava construir uma releitura das ações, padrões políticos, mentalidades e culturas políticas dentro de uma lógica motivada "pelo alto".

Raros são os estudos deste período que versam sobre a compreensão do mundo das camadas populares, dos homens e mulheres comuns, embora sejam tocados pela construção do Estado, pelos discursos de Getúlio Vargas e toda carga simbólica que ele representara. Ao mesmo tempo, podemos perguntar como a urbanização acelerada, o fortalecimento e consolidação de uma opinião pública, calcada no rádio, moldaram as vidas ou como esses elementos repercutiram no cotidiano da gente comum, pois coadjuvado com a imprensa escrita, irradiavam valores de um "novo" momento nacional.

Em grande medida, a impossibilidade de se alcançar os impactos das transformações daquela década se deveu, por um lado, pela própria perspectiva histórica de valorização da história política tradicional, pela resistência em ver na gente comum uma cultura ou capacidade de reação às ações do Estado. Por outro lado, inexistiam métodos capazes de perceber tais nuances específicas das camadas sociais mais pobres.

Esses limites começam a ser quebrados no Brasil a partir da década de 1980 quando, sob influência da micro-história, ocorre uma junção das análises com a eleição do cotidiano como campo de observação com o enfoque sociocultural. A preocupação aqui está em examinar como a classe operária (e não seus dirigentes) é formada, ou como ocorrem resistências populares a partir de uma "outra historia". O cotidiano é visto a partir do contraditório, revela tensões, desconexões aparentes, conflitos com os poderes e das resistências a esses poderes.

Henrique Espada (2006) argumentaria que seria importante o historiador olhar com atenção para as paisagens que aparentemente não se transformam. Sugere-se, portanto, que se tome, se não um procedimento, ao menos a qualidade de uma observação ou de uma perspectiva frente aos objetos da análise. Assim, a metodologia ou as fontes disponíveis para se chegar às pessoas comuns não são as mesmas que para se compreender o modo de pensar das grandes personalidades.

Como afirmavam E. P. Thompson, George Rudé e Eric Hobsbawm, as pessoas comuns quase que invariavelmente -, não deixaram documentos escritos para a posteridade e não tinham arquivos disponíveis para guardar as suas memórias. Dessa forma, um procedimento para auscultar este segmento social se faz através de um tratamento intensivo das fontes, ao seu modo peculiar de ler os indícios, isto é, a atenção do historiador deverá ser redobrada, ele deve estar atento a todos os detalhes, aos não ditos. Em diversas oportunidades ele está trabalhando ao nível das trajetórias 
individuais, da realidade cotidiana e de ardis recorrentes nas extensas redes de pequenos poderes onde os atores sociais se revelam em toda a sua humanidade.

Ao valer-se da metodologia e do enfoque micro-histórico, $O$ crime do restaurante chinês de Boris Fausto, vem cobrir parte desta lacuna do período do Estado Novo. O autor traz contribuições valiosas para o entendimento do modo de pensar e de como as pessoas comuns sobreviviam no interior de uma cidade de São Paulo em transformação.

$\mathrm{O}$ autor se relaciona com a micro-história ao considerar aspectos determinantes daquela metodologia, tais como a redução da observação do historiador. Fausto não se preocupa em tratar, por exemplo do Estado como ente privilegiado, ele busca apreciar ações humanas e significados que passam despercebidos quando se lida com grandes quadros

Do mesmo modo, para dar consubstanciação à sua proposta, ele concentra sua escala em pessoas comuns e não em grandes personagens, buscando ouvir suas vozes. Aqui, entra um terceiro elemento, pois há uma preocupação em extrair de fatos aparentemente corriqueiros uma dimensão sociocultural relevante.

Embora reconheça que sua obra possa ser lida como uma "boa história", Fausto marcará sua posição de historiador ao revelar dois aspectos imprescindíveis de seu trabalho. Embora apele para o recurso da narrativa, contraria a história das grandes estruturas, sem se confundir com o estilo das narrativas tradicionais, predominantes no século XIX. E, por fim, mas não menos importante, situa sua obra no terreno da história, o que significa apoiar-se nas fontes, delimitando assim, claramente, a obra ficcional.

No último ponto, Fausto retoma alguns ensinamentos de Carlo Ginzburg e suas preocupações em distinguir seu modo de construção narrativo da corrente que propugna por um ataque cético à cientificidade das narrações históricas (GINZBURG, 2007, p.10-13). Afirma que as narrações históricas não falariam da realidade, mas sim de quem as construiu. $O$ crime do restaurante chinês tem um estilo preferencial pela narrativa, admite Fausto, mas não a narrativa ficcional, pois a trama se apoia em fontes históricas, conclui o autor.

Em seu lugar, Fausto atuará mais como um camponês arando um terreno árido, procurará se situar mais como um "vasculhador" de testemunhos históricos a contrapelo, como Walter Benjamin sugeria, isto é, contra as intenções de quem os produziu.

Uma das grandes forças de $O$ crime do restaurante chinês é que sua escala de observação é reduzida. Vários personagens são pessoas comuns, invisíveis no plano dos grandes acontecimentos, que não figuram na galeria dos grandes mitos da história nacional. Contudo, dentro da proposta micro-histórica, o modo de pensar, as vidas e as interações das pessoas comuns servem para inserilas em um amplo contexto social que serve como chaves de entendimento de ângulos ignorados do 
contexto da época. São "fachos de luz, capazes de alcançar lugares escuros de uma sala que a luminária do teto não alcança", dir-nos-ia Boris Fausto.

$\mathrm{O}$ autor argumenta que a problemática só poderá ser entendida se compreender o contexto geral em que a vida das pessoas está envolvida. Assim, ele situará suas análises ao longo da repercussão do próprio crime do restaurante chinês, isto é, na São Paulo da década de 1930, ou, com maior incidência, nos anos que vão de 1938 a 1942. Naquele momento, a cidade não era a megalópole dos dias atuais. Todavia, ela já vivia os problemas dos grandes centros urbanos, sobretudo se considerarmos que nela já habitavam mais de 1 milhão de pessoas. Os vestígios do passado insistiam em não desaparecer, ainda que os meios de informação estivessem bastante disseminados, pela via dos jornais e das emissoras de rádio, que alcançavam não só a classe média como setores das classes populares. Outro aspecto da cidade era a presença de uma multiplicidade étnica, em grande medida resultante da imigração em massa de fins do século XIX e das primeiras décadas do século XX. "Em meados dos anos 1930, nela conviviam imigrantes e seus descendentes, velhos paulistanos em crescente minoria e migrantes internos que começavam a chegar em grande número, de Minas Gerais e do Nordeste" (FAUSTO, 2009, p.10).

Fausto reconhece que a obra está envolta de elementos de sua própria memória, pois parte do que ele retira dos relatos e da narrativa é decorrente das lembranças da sua infância, do carnaval de 1938, dos encontros familiares, das desgraças, etc. A memória reconstruída por Fausto é como uma fotografia de sua infância. O que foi lembrado é interessante na medida em que nos revela parte da trama.

O escritor admite que na sua memória "ficaram apenas as imagens do último carnaval [em família], do mistério sem rosto da morte da minha mãe. Ficaram também as imagens do crime do restaurante chinês, na versão em que Arias de Oliveira era considerado o autor da chacina" (FAUSTO, 2009, p.217), motivadas pelas cenas estampadas nos jornais, pelos comentários repercutindo o massacre.

No presente, ocorre um confronto entre o historiador e sua memória. A memória reconstruída do autor procura não o julgamento, mas a compreensão daquelas cenas, a partir das evidências, das fontes. O "juiz" transforma-se em historiador. Lembrar agora pode ser visto não como algo inocente, pois, olhando por trás dos ombros do delegado e nas tintas da imprensa que repercutia o crime, fica consciente de que, a autoridade depositada nestas instituições são elas mesmas apenas vozes contraditórias que se juntam ao processo.

As cenas que atormentavam um pequeno menino não deixavam de ser as da exposição de uma memória coletiva. As percepções de Boris Fausto, ainda que aparentemente passem à margem dos acontecimentos daqueles anos, implicam nas tramas que circundavam a sociedade: o crime, o 
futebol, o carnaval, as leituras que a imprensa construía sobre os envolvidos nos acontecimentos do carnaval de 1938 e a primária ideia de justiça.

O crime do restaurante chinês é uma chave de abertura dos caminhos mais amplos, seja ele o funcionamento do aparelho policial e judiciário - aqui estariam ausentes o uso da força como mecanismo de dominação e a obtenção da confissão do acusado negro Arias de Oliveira - , ou os novos mecanismos propugnados pela ciência criminológica, auxiliada pela psicologia e pelas técnicas desenvolvidas pelo professor positivista italiano Cesare Lombroso. Portanto, recorrentemente, estão contidas as teorias racistas, que procuravam demonstrar os tipos de homens capazes de cometer crimes e, consequentemente, a discussão da natureza da criminalidade e do perfil dos infratores.

Dividido em 16 capítulos curtos e objetivos, o livro é de fácil compreensão e acessibilidade (tanto para um leitor leigo quanto para um acadêmico). A obra conta o desenrolar do crime (ou chacina, como afirma o autor) do restaurante chinês, ocorrido no carnaval de 1938. No morticínio morreram o proprietário do restaurante, sua mulher e dois empregados do casal. Auxiliado pela riqueza de detalhes produzidos por jornais como o Estado de São Paulo, Folha da Manhã e Correio Paulistano, Fausto constrói a trama procurando problematizar e relativizar cada detalhe do crime. Coadjuvado pela imprensa, será na friúra do inquérito policial que ele procurará reconstruir a personalidade de todos os envolvidos. Contudo, o que o mundo da chacina revela, ao contrário de um mundo glamourizado, é a vida de "migrantes pobres, analfabetos ou semianalfabetos", alguns que com esforço vinham escalando alguns degraus da ascensão social (FAUSTO, 2009, p.41-43).

Seguindo uma ordem cronológica dos acontecimentos - que permite a compreensão do desenrolar dos acontecimentos -, não deixa de tocar nas intrigas e emaranhados que envolvem a trama, desde a existência de uma possível máfia chinesa, passando pela contrariedade de familiares do proprietário do restaurante chinês, as pressões "desatinadas" da imprensa sensacionalista, a busca pelos culpados, chegando ao negro Arias de Oliveira - o acusado de ter cometido o crime do restaurante chinês.

No ínterim da narrativa, Fausto percebe uma disputa política envolvendo, de um lado, a polícia que, pressionada pela repercussão popular de um grande crime, isto é, episódio que se destaca pela exuberância sangrenta, por envolver paixões amorosas, na importância dos protagonistas, ou por tudo isso junto (FAUSTO, 2009, p.39) que, na atualidade, se encontra banalizado não só pela generalização dos acontecimentos, mas, sobretudo, pela capacidade da imprensa em torná-los corriqueiros. De outro lado, ao chegar ao preto Arias, a ação da polícia desencadeia uma ação por parte da chamada burguesia "de cor", responsável por atividades culturais e pela criação de entidades como a Frente Negra Brasileira, que se propunha a lutar contra a discriminação racial. A Frente se colocara na defesa de Arias de Oliveira, evitando que ele ficasse 
desamparado ou nas mãos de um defensor público. Entra em cena, o jovem advogado Paulo Lauro, importante para as três absolvições que Arias receberia ao longo de três anos.

Ao lermos $O$ crime do restaurante chinês, a riqueza de fotografias nos transporta para os acontecimentos, permite que nos envolvamos cada vez mais na trama. Ao nos depararmos com a acusação de Arias de Oliveira, perguntamo-nos a cada momento qual será o desfecho dos acontecimentos.

O que podemos antecipar é que Arias de Oliveira volta à obscuridade, sem que o crime deixe de figurar na memória coletiva da cidade de São Paulo. Ele é memória coletiva para os militantes negros.

Do mesmo modo, pode ser compreendido como uma memória não rememorada de mil outros "Arias de Oliveira" que não tiveram o mesmo destino de se verem fora das prisões e suas vidas transformadas pelas agruras da justiça. Diante deste possível desfecho, fica cada vez mais provocativo pensarmos o potencial da construção historiográfica a partir de homens e de mulheres comuns que foram impactados pela nova ordem de coisas, pela ética do trabalho, pelo racismo, pela exclusão disseminada a partir da consolidação do capitalismo no Brasil, na São Paulo que era o seu exemplo mais concreto já a partir da década de 1920.

O livro de Boris Fausto é uma obra que contempla um jeito novo de fazer história: não perde a perspectiva de se construir conhecimento. Articula a relação entre o contar uma boa história (científica, porque baseada nas fontes) e uma outra (narrativa), ao gosto do leitor comum, que procura os prazeres de uma boa estória.

Resenha recebida em 03/2010. Aprovada em 05/2010. 